\title{
Comparison of shell-and-tube with plate heat exchangers for the use in low-temperature organic Rankine cycles ${ }^{\text {th }}$
}

\author{
Daniël Walraven $^{\mathrm{a}, \mathrm{c}}$, Ben Laenen ${ }^{\mathrm{b}, \mathrm{c}}$, William D'haeseleer ${ }^{\mathrm{a}, \mathrm{c}, *}$ \\ ${ }^{a}$ University of Leuven (KU Leuven) Energy Institute - TME branch (Applied Mechanics and Energy Conversion), \\ Celestijnenlaan 300A box 2421, B-3001 Leuven, Belgium \\ ${ }^{b}$ Flemish Institute for Technological Research (VITO), Boeretang 200, B-2400 Mol, Belgium \\ ${ }^{c}$ EnergyVille (joint venture of VITO and KU Leuven), Dennenstraat 7, B-3600 Genk, Belgium
}

\begin{abstract}
Organic Rankine cycles (ORCs) can be used for electricity production from low-temperature heat sources. These ORCs are often designed based on experience, but this experience will not always lead to the most optimal configuration. The ultimate goal is to design ORCs by performing a system optimization. In such an optimization, the configuration of the components and the cycle parameters (temperatures, pressures, mass flow rate) are optimized together to obtain the optimal configuration of power plant and components. In this paper, the configuration of plate heat exchangers or shell-and-tube heat exchangers is optimized together with the cycle configuration. In this way every heat exchanger has the optimum allocation of heat exchanger surface, pressure drop and pinch-point-temperature difference for the given boundary conditions. ORCs with plate heat exchangers perform mostly better than ORCs with shell-and-tube heat exchangers, but one disadvantage of plate heat exchangers is that the geometry of both sides is the same, which can result in an inefficient heat exchanger. It is also shown that especially the cooling-fluid inlet temperature and mass flow have a strong influence on the performance of the power plant.
\end{abstract}

Keywords: ORC, Shell-and-tube heat exchanger, Plate heat exchanger, System optimization

\section{Introduction}

Low-temperature geothermal heat sources are widely available [1], but the electricity production efficiency is low due to the low temperature. Many authors have tried to maximize the electricity production efficiency of organic Rankine cycles (ORCs) [2-4] by optimizing the cycle parameters (pressures, temperatures and mass flow rates). To perform such an optimization, simplifying assumptions are made about the components, but these assumptions can have a strong influence on the performance and the cost of the ORC.

As already explained in our previous work [5], this issue is already touched upon in the literature. Madhawa Hettiarachchi et al. [6] minimized the ratio of the total heat-exchanger surface and the net electrical power produced by the cycle, for a fixed heat-exchanger configuration. Quoilin et al. [7] developed an ORC model and plate heat exchanger models based on their experimental set-up, while neglecting the pressure drop in the heat exchangers. They used these models to predict the performance of their set-up in different working conditions. Shengjun et al. [8] maximized the performance of ORCs with shell-and-tube heat exchangers, while keeping the configuration of the heat exchangers fixed. Domingues et al. [9] optimized ORCs with shell-and-tube heat exchangers for vehicle exhaust waste heat recovery and investigated the effect of the

\footnotetext{
Published version: http://dx.doi.org/10.1016/j.enconman.2014.07.019

*Corresponding author. Tel.: +32 163225 11; fax: +32 16322985.

Email addresses: Daniel.Walraven@mech.kuleuven.be (Daniël Walraven), Ben.Laenen@vito.be (Ben Laenen), William.Dhaeseleer@mech.kuleuven.be (William D'haeseleer)
} 
number of tubes in the shell-and-tube heat exchangers on the performance of the ORC. Another approach was followed by Franco and Villani [10]. They divided the ORC in a system level and a component level. In a first step, the system level was optimized, followed by the optimization of the configuration of the components for the obtained optimal system configuration. An iteration between the optimization of both levels was needed to come to the final solution.

To obtain the global optimum configuration of the ORC, the system and the components should be optimized together so that the configuration of the components is optimal for the use in the cycle and so that the components are adjusted to each other. To perform such a system optimization, realistic models, which describe the performance of the components depending on geometric parameters, are needed.

In this paper models for heat exchangers are implemented and included in the system optimization. Both shell-and-tube heat exchangers and plate heat exchangers are discussed. In previous research [5] we have performed a detailed investigation of shell-and-tube heat exchangers integrated in ORCs. The shell-and-tube heat exchangers are modeled with the Bell-Delaware method [11, 12], which is a mature model and can be used for single-phase flow, condensing and evaporation.

The purpose of our research reported in this paper is to integrate plate heat exchangers in ORCs and to compare the result to that obtained with shell-and-tube heat exchangers. Martin [13] developed a model for plate heat exchangers with single-phase flow. This model is based on physical reasoning and many experimental data are used. Such generally applicable models do not exist for two-phase plate heat exchangers used as evaporators or condensers, although much research has been performed on the topic [14-20]. The authors of those references propose correlations for heat-transfer coefficient and pressure drop based on own experiments and these correlations are therefore only valid for the investigated cases. We shall utilize the correlations of Han et al. [16] and Han et al. [17] for evaporation and condensation in plate heat exchangers, respectively. These papers correlate the performance of plate heat exchangers to many geometrical parameters.

This paper extends the work performed in Walraven et al. [5], in which ORCs with shell-and-tube heat exchangers are optimized for a reference case. The conclusion from that work is that it is optimal to use the $30^{\circ}$ and $60^{\circ}$ tube configurations in single and two-phase heat exchangers, respectively. In this paper, models for plate heat exchangers are added and ORCs with plate heat exchangers are compared to ORCs with shell-and-tube heat exchangers (with the optimal tube configuration). The influence of the heat-source-inlet temperature, heat-source-outlet temperature, total heat exchanger surface, cooling-fluid inlet temperature and the cooling fluid mass flow rate on the performance of the power plant are also investigated. The comparison between ORCs with the two different types of heat exchangers is performed in a wide range of parameters and for many fluids.

\section{Organic Rankine cycle}

Different types of ORCs exist and are simulated in this paper. The investigated cycles can be of the simple or recuperated type, be subcritical or transcritical and can have one or two pressure levels. Two examples are given in figure 1, in which the scheme of a single-pressure, recuperated ORC and a double-pressure, simple ORC are shown. All the possible heat exchangers (economizer, evaporator, superheater, desuperheater, condenser and recuperator) are shown in the figure, but are not always necessary.

In all configurations it is assumed that state 1 is saturated liquid and that the isentropic efficiencies of the pump and turbine are 80 and $85 \%$, respectively. More information of the modeling can be found in previous work $[4,5]$. Instead of assuming a fixed pinch point temperature difference and ideal heat exchangers, models are used to calculate the heat transfer coefficients and pressure drops in each heat exchanger. 


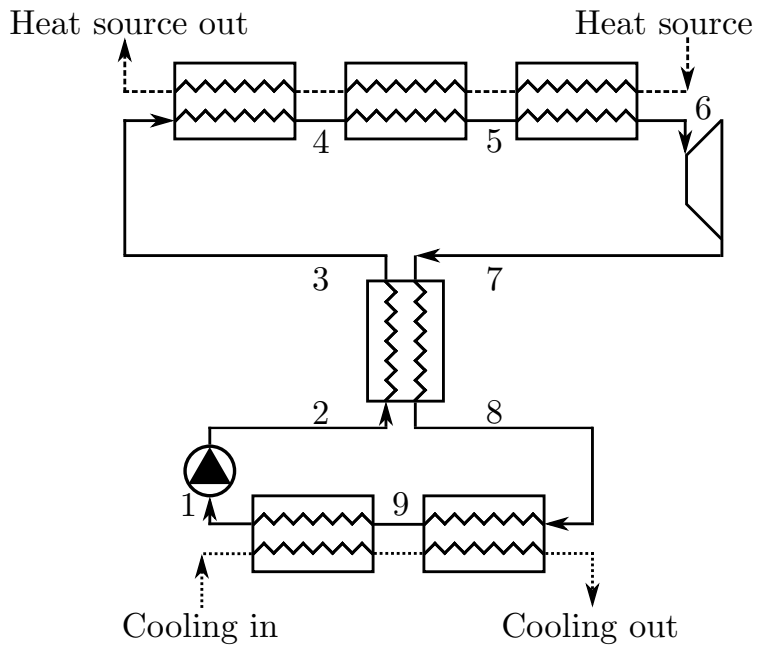

(a) Single-pressure

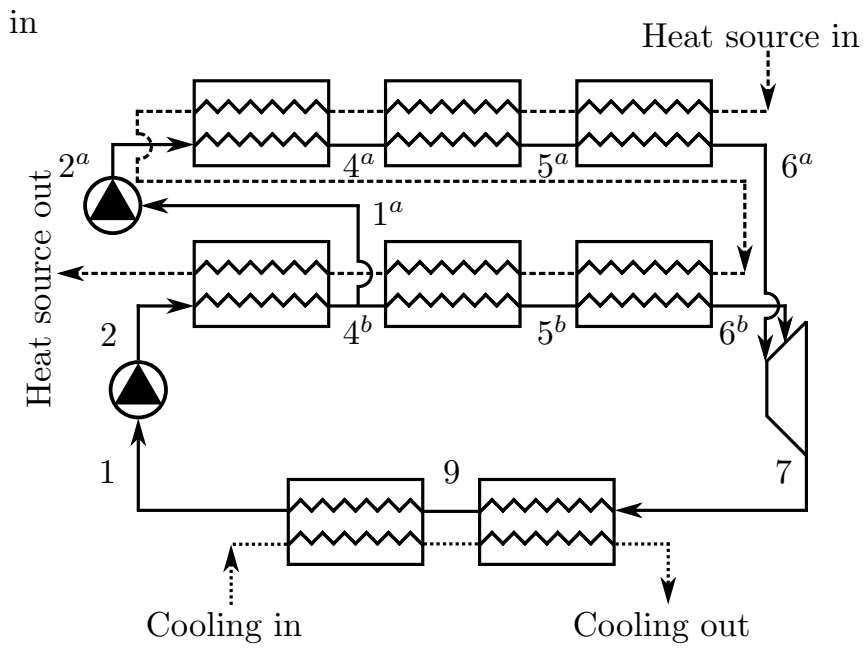

(b) Double-pressure

Figure 1: Scheme of a single-pressure, recuperated (a) and double-pressure, simple (b) ORC.

\section{Shell-and-tube heat exchanger}

The shell-and-tube heat exchanger type has already been studied in Walraven et al. [5]. Here we now recall some elements to support the later analysis with plate heat exchangers. TEMA E type heat exchangers with a single shell pass and with the inlet and the outlet at the opposite ends of the shell are modeled. The working fluid always flows on the shell side, so models for the pressure drop and heat-transfer coefficient in single-phase flow, evaporation and condensation in a TEMA E shell are needed. The tube-side fluid (the heat source) will always be single phase.

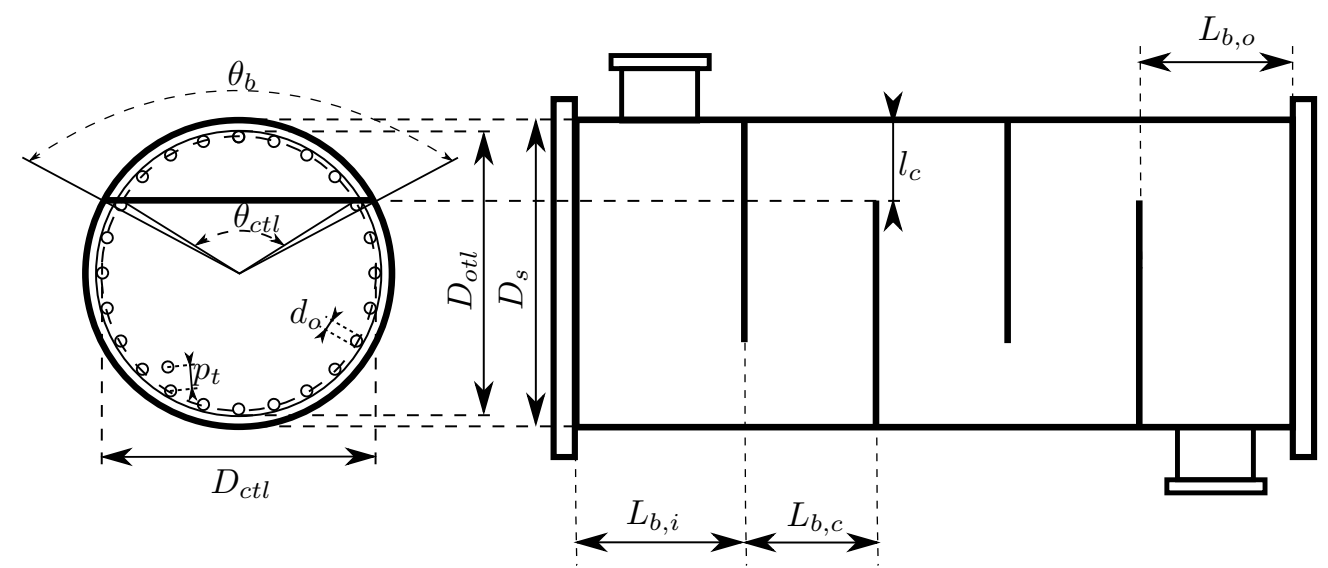

Figure 2: Shell-and-tube geometrical characteristics. Figure adapted from Shah and Sekulić [12]. See also Walraven et al. [5].

Figure 2 recalls the basic geometrical characteristics of a shell-and-tube heat exchanger. These are the shell outside diameter $D_{s}$, the outside diameter of a tube $d_{o}$, the pitch between the tubes $p_{t}$, the baffle cut length $l_{c}$ and the baffle spacing at the inlet $L_{b, i}$, outlet $L_{b, o}$ and the center $L_{b, c}$. More detailed information about the shell-and-tube model used in this paper can be found in Walraven et al. [5]. 


\section{Plate Heat Exchanger}

Plate heat exchangers can have many different types of corrugations [12], but in this paper only heat exchangers with chevron, also known as herringbone, corrugations are used. This type of corrugation is commonly used and models which describe the pressure drop and heat transfer depending on the heat exchanger geometry are available $[13,16,17]$. The number of passes on both sides of the heat exchangers are assumed to be equal in this paper.

\subsection{Geometry}

Figure 3 shows the geometrical parameters of a chevron plate. The corrugations are determined by the corrugation amplitude $a$, the corrugation width $\Lambda$ and the angle of the corrugations $\beta$. The width of a plate $W$, the length of a plate between ports $L_{p}$ and the length of a plate for heat transfer $L_{h}$ are also indicated.

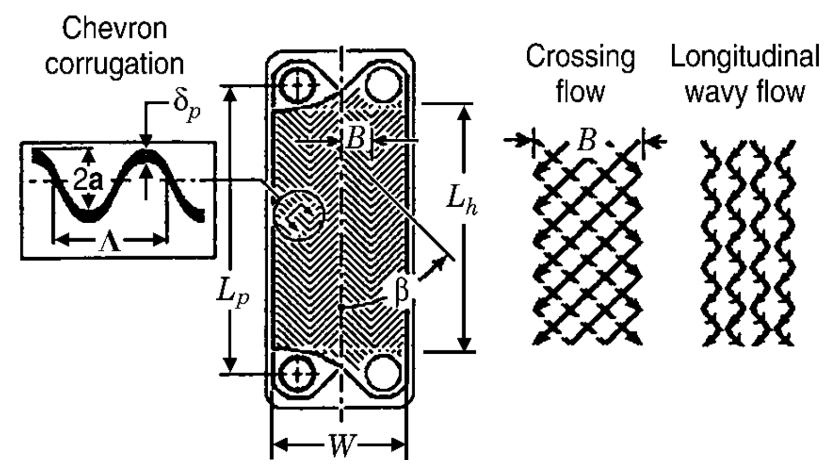

Figure 3: Geometrical parameters of a chevron plate. Figure from Shah and Sekulić [12].

The hydraulic diameter is defined as:

$$
D_{h}=\frac{4 a}{\Phi}
$$

where $\Phi=\frac{1}{6}\left(1+\sqrt{1+X^{2}}+4 \sqrt{1+X^{2} / 2}\right)$ is the area-enlargement factor and $X=\frac{2 \pi a}{\Lambda}$ the dimensionless corrugation parameter.

\subsection{Heat-transfer and pressure-drop correlations}

The correlations of Martin [13] are used to predict the heat-transfer coefficient and the pressure drop in the single-phase heat exchangers. For the evaporator and the condenser, the correlations of Han et al. [16] and Han et al. [17] are used, respectively. An overview of these correlations is given in Appendix A.

\subsection{Implementation of the models}

To account for non-uniform fluid properties, each heat exchanger is divided into five parts with an equal heat load ${ }^{1}$. This number is chosen, because it leads to a reasonable accuracy and calculation time. For each heat exchanger, the configuration $\left(a, \Lambda, \beta\right.$ and $\left.W N_{p}\right)$, the inlet states at one side of the heat exchanger and a necessary outlet condition (e.g. the working fluid has to be saturated vapor at the end of the evaporator) are needed. The variables $W$ and $N_{p}$ are combined to one variable, because only their product appears in the equations. With these data, the total heat that has to be transferred in the case of no pressure drop ${ }^{2}$ can be calculated. In each of the five parts one fifth of this total heat will be exchanged. With the equations above, the heat-transfer coefficient and the pressure drop in the first part can be calculated. In this way, the state after the first part, the necessary heat-transfer surface and the fictive plate length of the first part can be calculated. This procedure is repeated for the other parts, except in the last part for which the heat to be transferred is corrected for the pressure drop in the previous parts.

\footnotetext{
${ }^{1}$ These parts generally do not have the same physical size.

${ }^{2}$ This is a starting value. The effect of the pressure drop on the heat load is taken into account in the last part of the heat exchanger.
} 


\section{Optimization}

\subsection{Objective function}

The goal of the optimization is to find a system configuration which maximizes the mechanical work output for a given heat source. This is the same as maximizing the exergetic plant efficiency [4], defined as:

$$
\eta_{\text {ex }}^{\text {plant }}=\frac{\dot{W}_{\text {net }}}{\dot{m}^{\text {source }} e_{\text {in }}^{\text {source }}}
$$

with $\dot{W}_{n e t}$ the net mechanical-power production of the power plant, $\dot{m}^{\text {source }}$ the mass flow of the source and $e_{i n}^{\text {source }}$ the flow exergy of the source.

\subsection{Optimization variables and constraints}

The optimization variables which determine the cycle configuration in a single-pressure, simple cycle are the temperature and saturation temperature at the pressure before the turbine $T_{6}$ and $T^{s a t}\left(p_{6}\right)$, the mass flow of working fluid $\dot{m}_{w f}$ and the temperature after the condenser $T_{1}$. For a recuperated cycle, the temperature difference between states 2 and 8 is added as an optimization variable. For a double-pressure cycle, $T_{6}^{b}$, $T^{s a t}\left(p_{6}^{b}\right)$ and $\dot{m}_{w f}^{b}$ are added as optimization variables. More information can be found in Walraven et al. [5].

The optimization variables and constraints used for the plate-type heat exchangers are given in table 1.

\begin{tabular}{lcc}
\hline Optimization variable & Lower boundary & Upper boundary \\
\hline Corrugation amplitude $a$ & $1 \mathrm{~mm}$ & $200 \mathrm{~mm}$ \\
Corrugation width $\Lambda$ & $1 \mathrm{~mm}$ & $200 \mathrm{~mm}$ \\
Corrugation angle $\beta$ & $0^{\circ}$ & $90^{\circ}$ \\
Product of plate width and number of channels $W N_{p}$ & $10 \mathrm{~mm}$ & $10 \mathrm{~m}$ \\
\hline Ratio of corrugation width to corrugation amplitude $\Lambda / a$ & 2.5 & 3.5 \\
\hline
\end{tabular}

Table 1: Optimization variables and constraints used for plate-type heat exchangers and their lower and upper boundaries.

If no constraint on the heat-exchanger surface of each heat exchanger is imposed, the pinch-point-temperature differences would become very small and the total heat exchanger surface would become huge. Therefore, a non-linear constraint ${ }^{3}$ on the total heat exchanger surface of all heat exchangers together $A^{\text {tot }}$ is imposed: $A^{\text {tot }} \leq A_{\text {max }}^{\text {tot }}$. In this way, the optimizer can choose itself how to distribute the available surface optimally amongst the different heat exchangers.

A last constraint is a limit on the heat source outlet temperature. In some circumstances, the heat source outlet temperature cannot be too low, e.g. to use the heat source for heating or to avoid scaling with geothermal brines. This is again a non-linear constraint: $T_{\text {out }}^{\text {source }} \geq T_{\text {min }}^{\text {source }}$.

Table 2 recalls the optimization variables and constraints for the shell-and-tube case, analyzed in Walraven et al. [5].

\subsection{Optimization approach}

The cycle configuration is optimized together with the configuration of the heat exchangers, as done in Walraven et al. [5]. This means that all the above mentioned optimization variables can be adapted at every iteration step by the optimizer in order to maximize the exergetic plant efficiency. Fluid properties are

\footnotetext{
${ }^{3} A^{\text {tot }}$ is a non-linear function of the optimization variables.
} 


\begin{tabular}{lcc}
\hline Optimization variable & Lower boundary & Upper boundary \\
\hline Shell diameter $D_{s}$ & $0.3 \mathrm{~m}$ & $2 \mathrm{~m}$ \\
Tube outside diameter $d_{o}$ & $5 \mathrm{~mm}$ & $50 \mathrm{~mm}$ \\
Relative tube pitch $p_{t} / d_{o}$ & 1.15 & 2.5 \\
Relative baffle cut $l_{c} / D_{s}$ & 0.25 & 0.45 \\
Baffle spacing $L_{b, c}$ & $0.3 \mathrm{~m}$ & $5 \mathrm{~m}$ \\
\hline Ratio of tube diameter to shell diameter $d_{o} / D_{s}$ & $/$ & 0.1 \\
\hline
\end{tabular}

Table 2: Optimization variables and constraints used for shell-and-tube heat exchangers and their lower and upper boundaries.

obtained from REFPROP [21] and the complex-step derivative method [22] is used to obtain the derivative of the fluid properties. These properties are available in Python, in which our model is written, by using F2PY [23]. The CasADi software [24] calculates the gradient of the objective function and constraints with automatic differentiation in reverse mode and these gradients are used by the optimizer WORHP [25] together with the value of the objective function to find the optimum.

\section{Results}

\subsection{Reference parameters}

$100 \mathrm{~kg} / \mathrm{s}$ of clean water is used as the heat source. The parameters for the reference case are given in table 3. The influence of these parameters is investigated in the following sections. The temperature of the heat source after the ORC is unconstrained and the ORC is of the simple, single-pressure type. In a previous work [5] it was shown that it is best to use a $30^{\circ}$ - and $60^{\circ}$-tube configuration in single-phase and two-phase shell-and-tube heat exchangers, respectively. This combined configuration is used for the comparison in this paper.

\begin{tabular}{llc}
\hline Parameter & Symbol & Value \\
\hline Heat source inlet temperature & $T_{i n}^{\text {source }}$ & $125^{\circ} \mathrm{C}$ \\
Heat source mass flow & $\dot{m}^{\text {source }}$ & $100 \mathrm{~kg} / \mathrm{s}$ \\
Maximum allowed heat exchanger surface & $A_{\text {max }}^{\text {tot }}$ & $4000 \mathrm{~m}^{2}$ \\
Cooling fluid inlet temperature & $T_{\text {in }}^{\text {cooling }}$ & $20^{\circ} \mathrm{C}$ \\
Cooling fluid mass flow & $\dot{m}^{\text {cooling }}$ & $800 \mathrm{~kg} / \mathrm{s}$ \\
\hline
\end{tabular}

Table 3: Reference parameters.

\subsection{Influence maximum allowed heat-exchanger surface}

In this section the influence of the maximum allowed heat exchanger surface is investigated. The other parameters are the ones given in table 3. Figure 4 shows the exergetic plant efficiency for simple ORCs with all plate heat exchangers or all shell-and-tube heat exchangers for different working fluids as a function of the maximum allowed heat exchanger surface. The efficiency increases with increasing $A_{m a x}^{\text {tot }}$, as expected.

This increase of the exergetic plant efficiency with increasing maximum allowed surface is explained by the increase of the energetic cycle efficiency (figure 5) and the decrease of the heat-source outlet temperature (figure 6). So, more heat is added to the cycle and this heat is converted more efficiently to mechanical power when the total heat-exchanger surface increases. This cycle efficiency is defined as:

$$
\eta_{e n}^{c y c l e}=\frac{\dot{W}_{n e t}}{\dot{Q}}
$$

with $\dot{Q}$ the heat added to the cycle. 


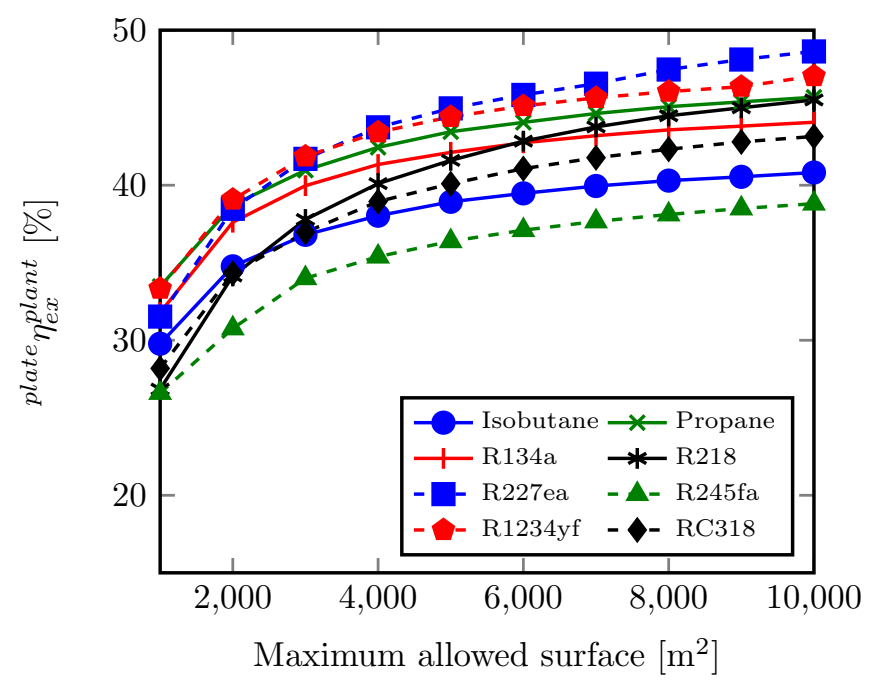

(a) Plate heat exchangers

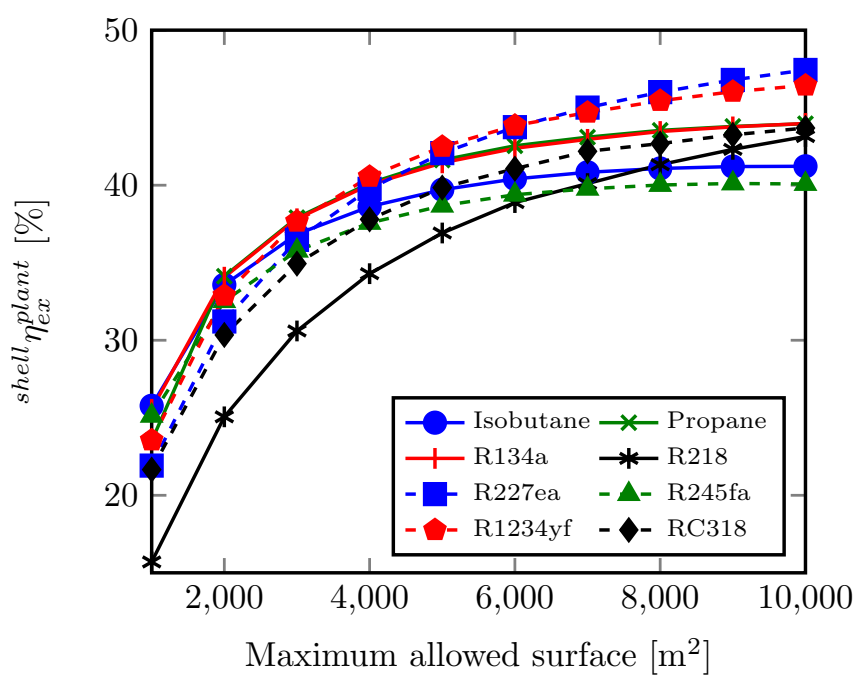

(b) Shell-and-tube heat exchangers

Figure 4: Exergetic plant efficiency for single-pressure, simple ORCs with all plate heat exchangers (a) and all shell-and-tube heat exchangers (b) for different fluids.

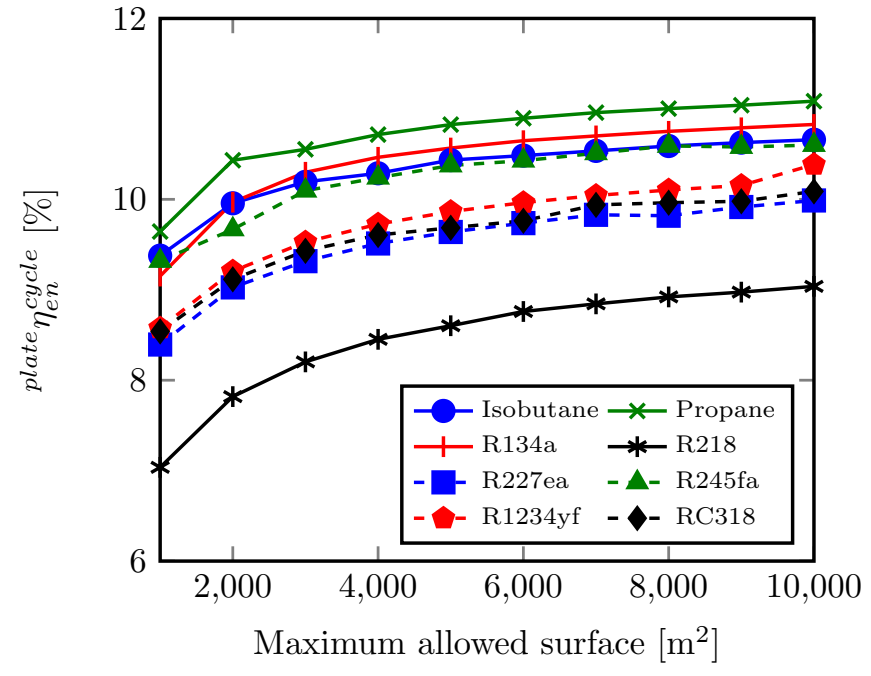

(a) Plate heat exchangers

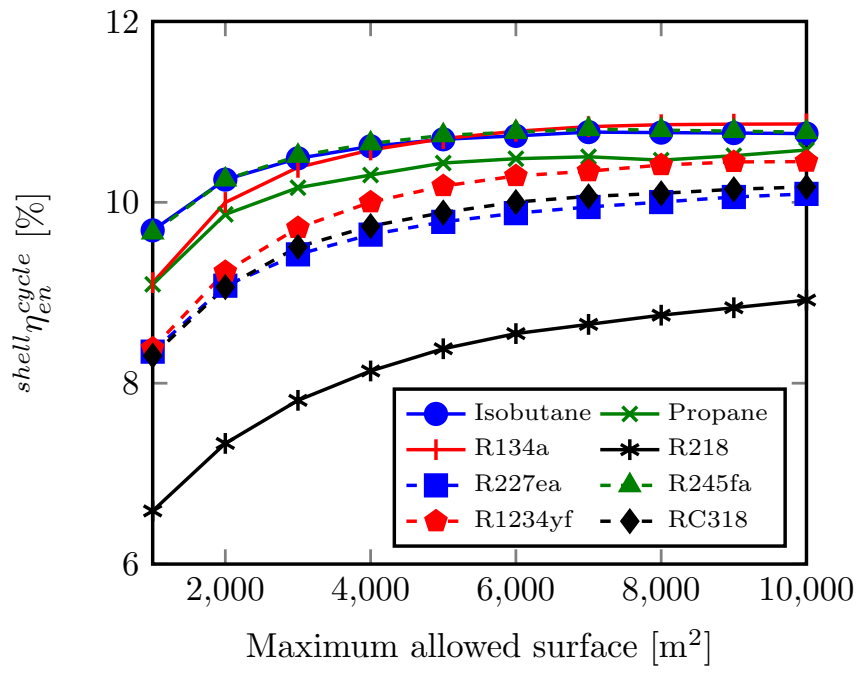

(b) Shell-and-tube heat exchangers

Figure 5: Energetic cycle efficiency for single-pressure, simple ORCs with all plate heat exchangers (a) and all shell-and-tube heat exchangers (b) for different fluids.

For low values of $A_{\max }^{\text {tot }}$ ORCs with all plate heat exchangers produce more electrical power than ORCs with all shell-and-tube heat exchangers. It is generally known that plate heat exchangers can achieve higher heat-transfer coefficients and therefore lower pinch-point-temperature differences as seen in figure 7 . For high values of $A_{\text {max }}^{\text {tot }}$ ORCs with all shell-and-tube heat exchangers perform equally well or even better. The pinch-point temperature differences in figure 7 become very small and the efficiency of the ORCs almost reaches the upper limit. 


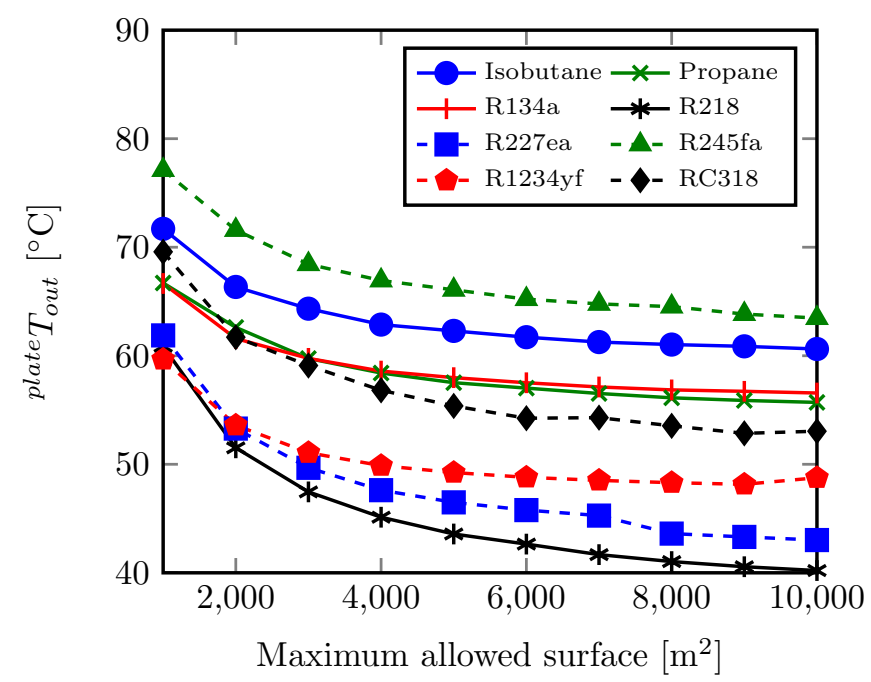

(a) Plate heat exchangers

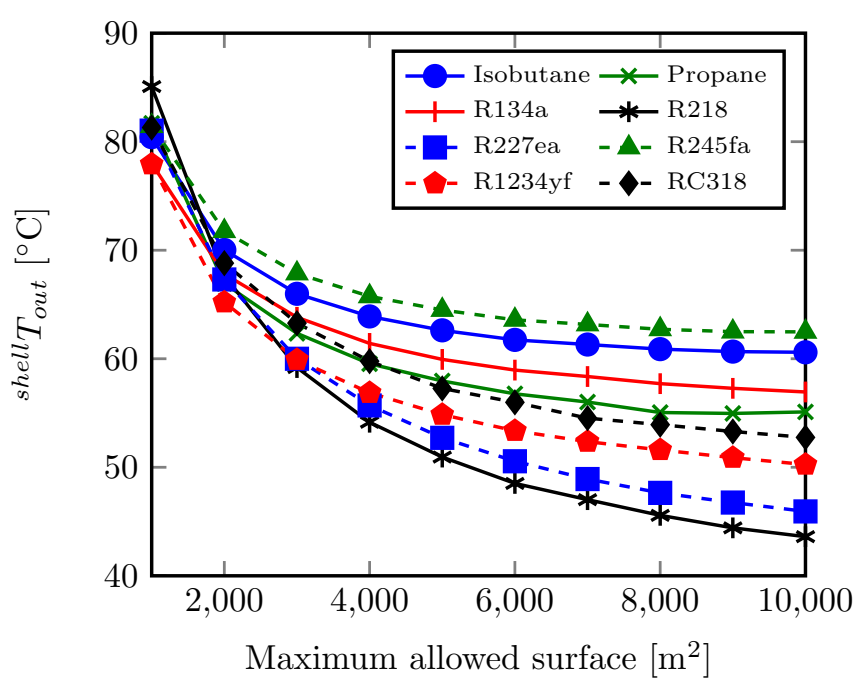

(b) Shell-and-tube heat exchangers

Figure 6: Outlet temperature of the heating fluid for single-pressure, simple ORCs with all plate heat exchangers (a) and all shell-and-tube heat exchangers (b) for different fluids.

For the working fluids R245fa, isobutane and RC318 the exergetic plant efficiency of ORCs with all shelland-tube heat exchangers is better than the one for ORCs with all plate heat exchangers for $A_{\text {max }}^{\text {tot }}>$ 2000,3000 and $6000 \mathrm{~m}^{2}$, respectively. Comparison of figures $7 \mathrm{a}$ and $7 \mathrm{~b}$ shows that the pinch-point temperature difference between the working fluid and cooling fluid $\Delta T_{\text {min }}^{\text {Low }}$ decreases much faster in the case of shell-and-tube heat exchangers with increasing $A_{\max }$. This is due to fact that the cold and the hot side of plate heat exchangers with the same number of passes at both sides have exactly the same geometry, which is of course not the case for shell-and-tube heat exchangers. The mass flow of the cooling water is much higher than the one of the working fluid, which can result in a large difference between the optimal geometry of the cold side and the one of the hot side in a plate heat exchanger, leading to relatively high pinch-point-temperature differences.

It can also be noticed from figure 7 that $\Delta T_{\min }^{H i g h}$ is lower than $\Delta T_{\text {min }}^{\text {Low }}$ for subcritical cycles (e.g. Isobutane, R245fa), while they are about equal for transcritical cycles (e.g. R227ea, R1234yf). Because of the high cooling fluid mass flow, $\Delta T_{\min }^{\text {Low }}$ is relatively close to the average temperature difference, which applies also to $\Delta T_{m i n}^{H i g h}$ in transcritical cycles. In subcritical cycles, $\Delta T_{m i n}^{H i g h}$ is much lower than the average temperature difference.

\subsection{Influence heat-source inlet temperature}

In this section the heat-source inlet temperature is varied between 100 and $150^{\circ} \mathrm{C}$, while keeping the other parameters constant as given in table 3. It is seen from figure 8 that every fluid performs optimally for a certain heat source-inlet temperature ${ }^{4}$. ORCs with all shell-and-tube heat exchangers have their maximum plant efficiency at a lower heat-source inlet temperature than plate heat exchangers. A heat source with an higher inlet temperature contains more energy and more energy will be transfered in the heat exchangers. However, for a fixed maximum allowed heat-exchanger surface, the pinch-point-temperature differences will increase with increasing heat-source inlet temperature. This increase will in most cases be faster if shell-andtube heat exchangers are used instead of plate heat exchangers. Higher pinch-point-temperature differences

\footnotetext{
${ }^{4}$ For some fluids this optimal temperature is outside the range of the figure
} 


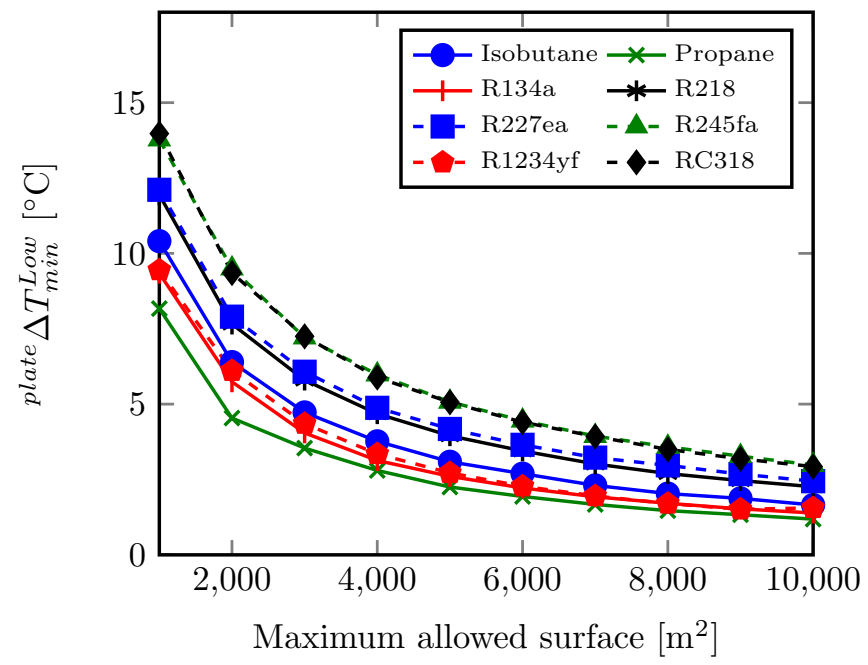

(a) Plate heat exchangers, $\Delta T_{\min }$ between working fluid and cooling fluid

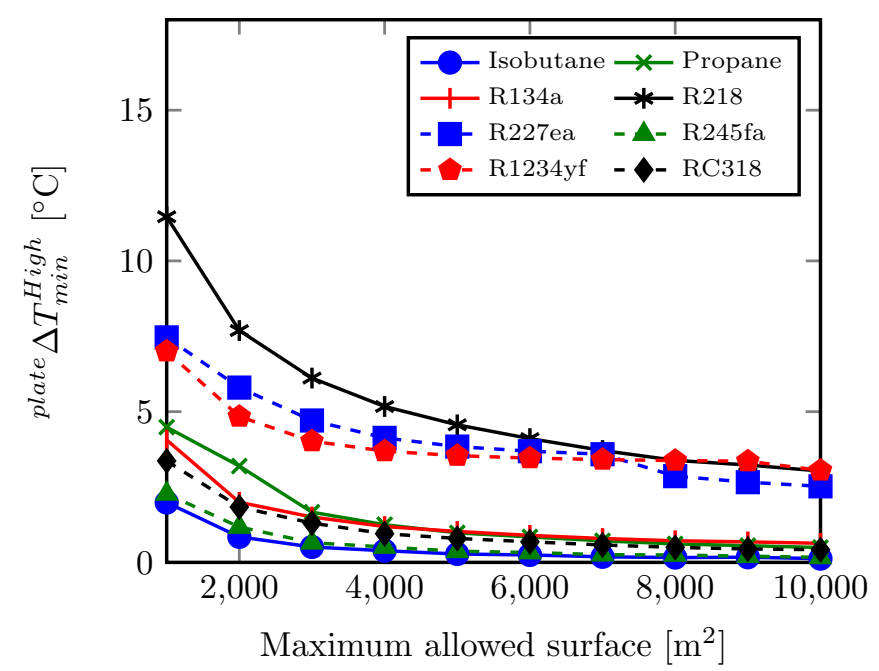

(c) Plate heat exchangers, $\Delta T_{\min }$ between heating fluid and working fluid

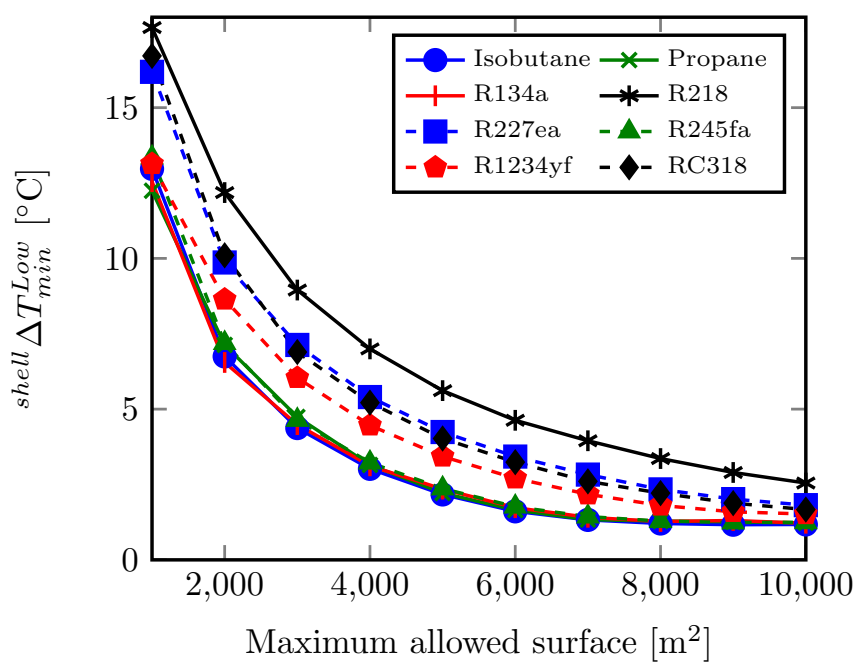

(b) Shell-and-tube heat exchangers, $\Delta T_{\min }$ between working fluid and cooling fluid

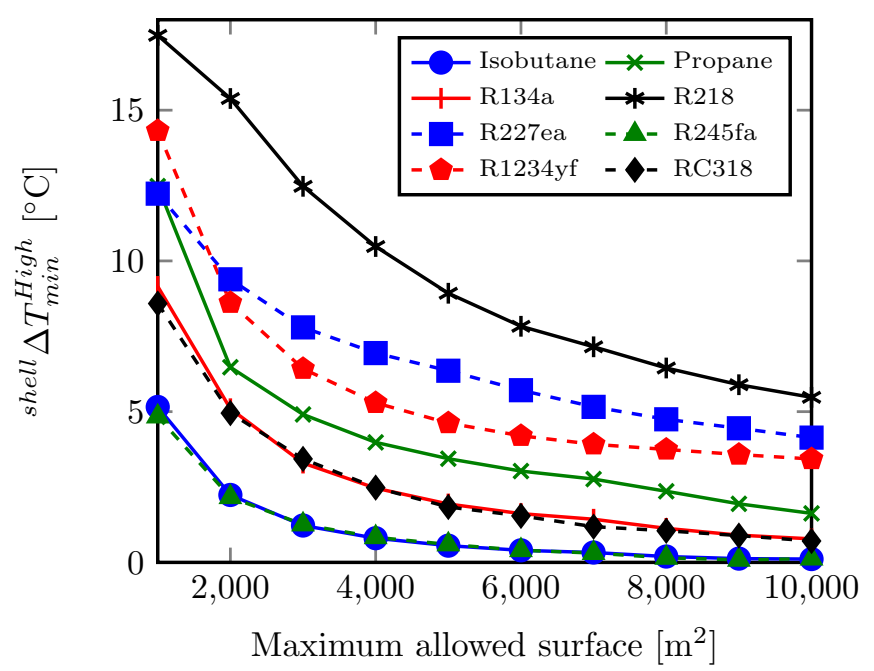

(d) Shell-and-tube heat exchangers, $\Delta T_{\min }$ between heating fluid and working fluid

Figure 7: Minimum temperature difference between working fluid \& cooling fluid $(\mathrm{a}, \mathrm{b})$ and minimum temperature difference between heating fluid and working fluid $(\mathrm{c}, \mathrm{d})$ for single-pressure, simple ORCs with all plate heat exchangers $(\mathrm{a}, \mathrm{c})$ and all shell-and-tube heat exchangers (b, d) for different fluids.

have of course a negative influence on the exergetic plant efficiency and this efficiency will therefore start to decrease earlier when shell-and-tube heat exchangers are used instead of plate heat exchangers.

\subsection{Influence heat-source outlet temperature}

Often the heat source cannot be cooled down too much; e.g. to avoid scaling in geothermal brines or when the heat source after the ORC is used for heating. In this section, the heat-source outlet temperature will be limited to values between 40 and $90^{\circ} \mathrm{C}$. The other values are the same as in the reference case (table 3 ), but only the results for ORCs with all plate heat exchangers are given. Both simple and recuperated, single-pressure cycles are investigated. 


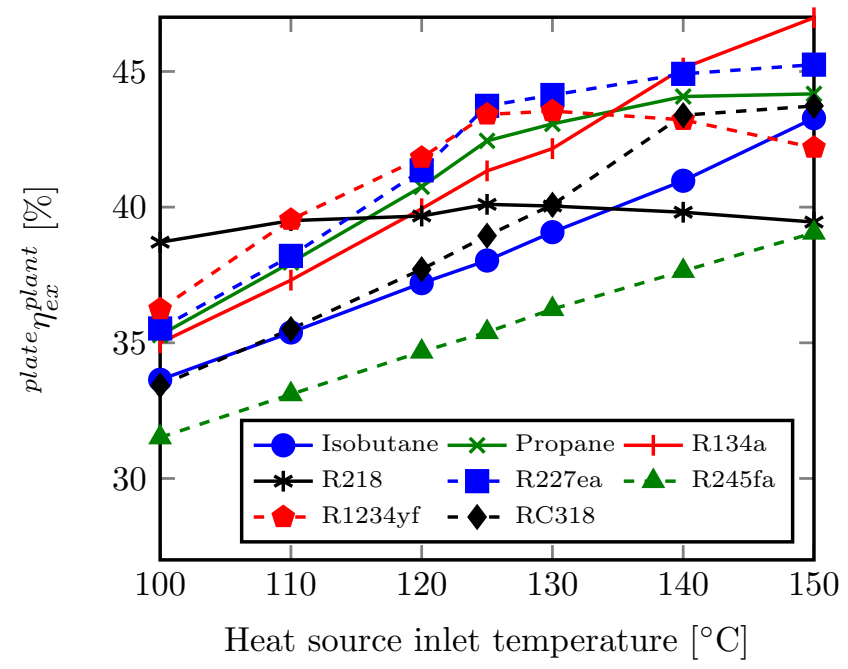

(a) Plate heat exchangers

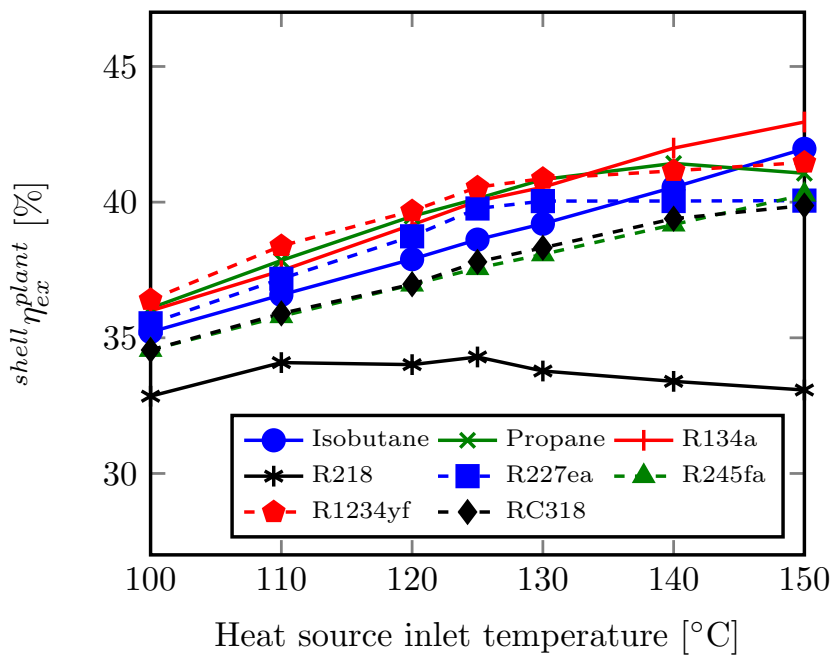

(b) Shell-and-tube heat exchangers

Figure 8: Exergetic plant efficiency for single-pressure, simple ORCs with all plate heat exchangers (a) and all shell-and-tube heat exchangers (b) for different fluids. The parameters are those of Table 3.

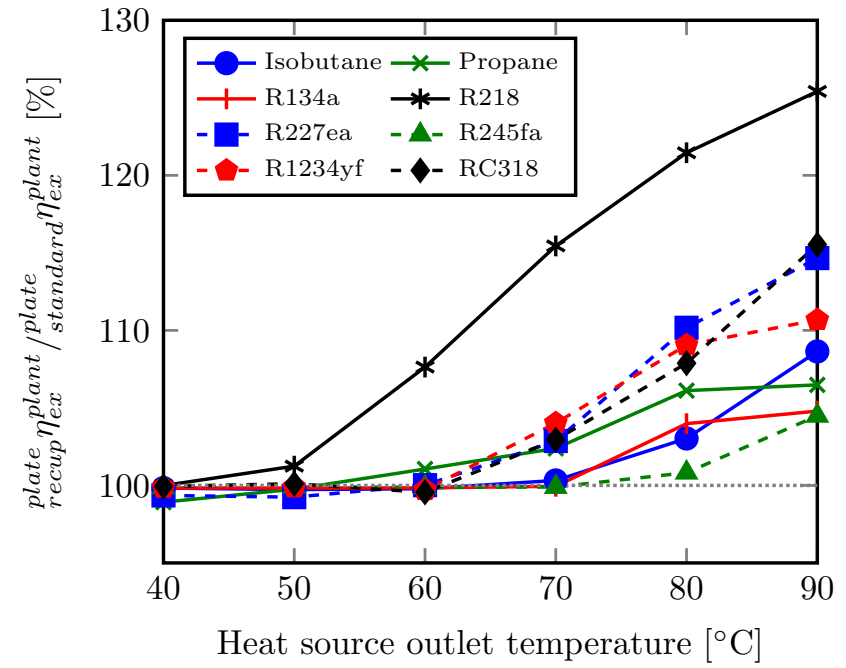

(a) Simple cycle

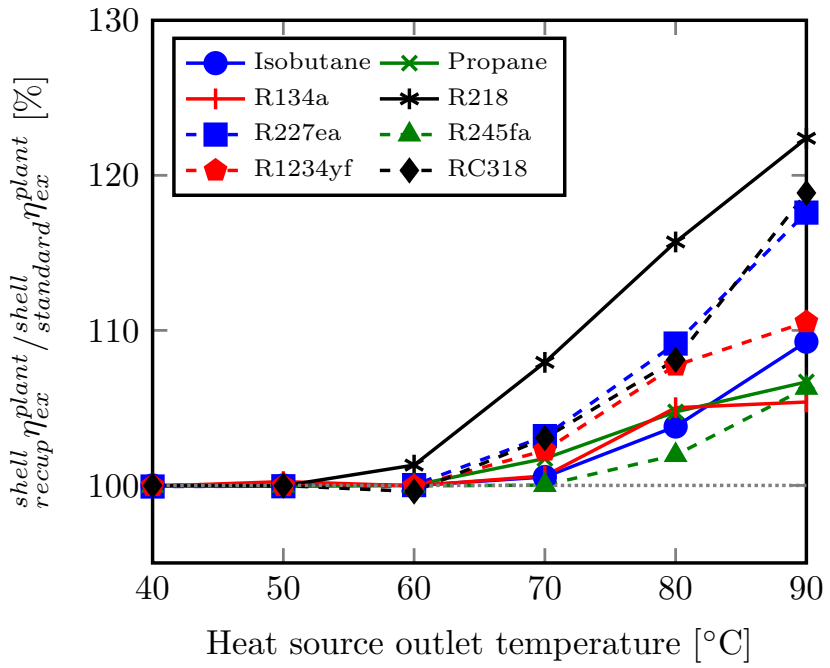

(b) Recuperated cycle

Figure 9: Exergetic plant efficiency for single-pressure, simple ORCs (a) and recuperated ORCs (b) with all plate heat exchangers for different fluids. Other parameters are those of Table 3.

Figure 9 shows the comparison between simple and recuperated cycles. When the heat-source outlet temperature is limited to a relatively low temperature, both type of cycles perform equally wel as explained in Walraven et al. [4]. When the limit is set at a higher temperature, the recuperated cycles perform better than the simple ones. The internal heat recuperation increases the cycle efficiency, which leads to a higher plant efficiency for a fixed heat-source outlet temperature. 


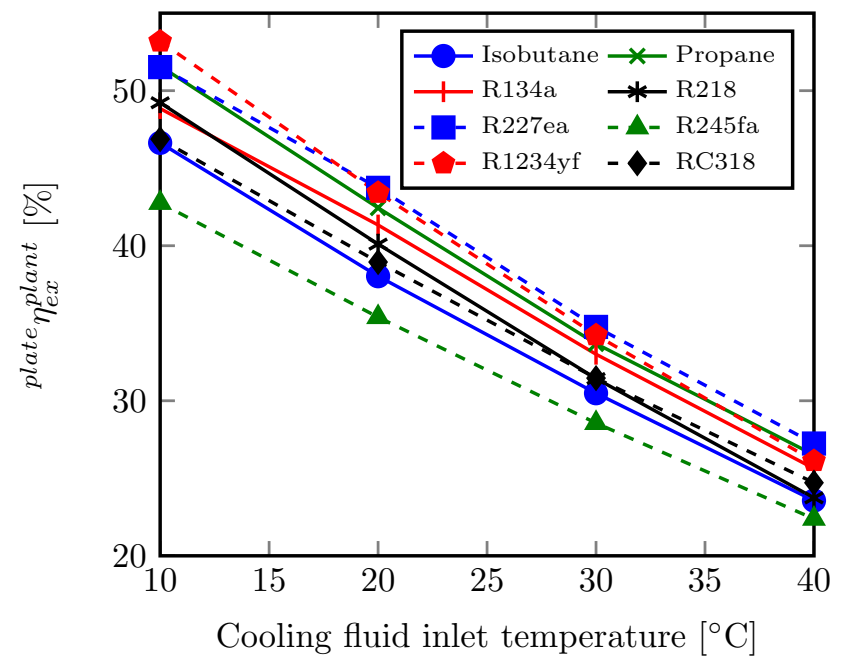

(a) Exergetic plant efficiency

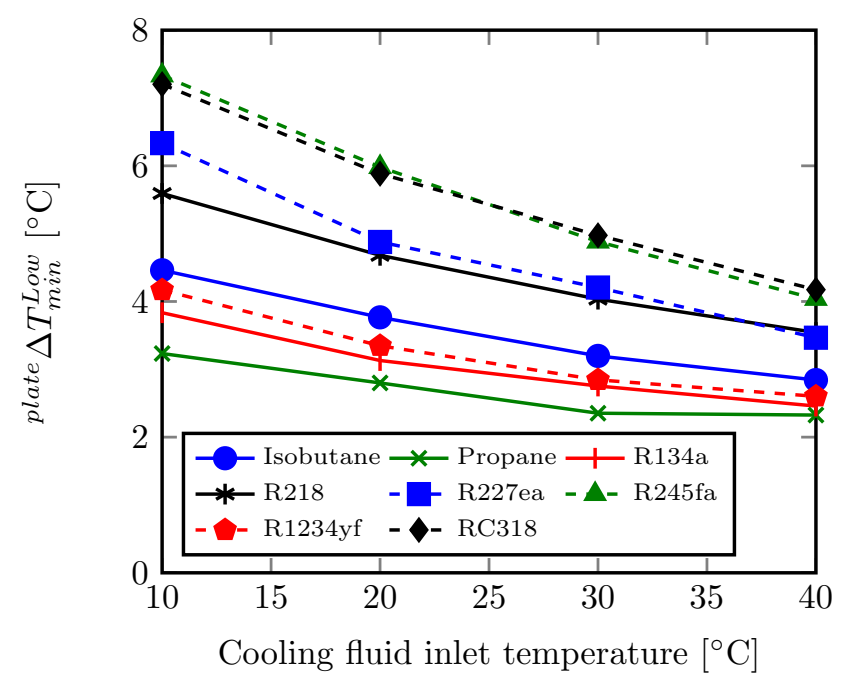

(b) $\Delta T_{\min }$ between working fluid and cooling fluid

Figure 10: Exergetic plant efficiency (a) and $\Delta T_{\text {min }}^{\text {Low }}$ (b) for single-pressure, simple ORCs with all plate heat exchangers for different fluids. Other parameters are those of Table 3.

\subsection{Influence cooling-fluid inlet temperature}

The cooling-fluid inlet temperature is varied between 10 and $40^{\circ} \mathrm{C}$, while keeping the other parameters constant (table 3). Only the results for ORCs with all plate heat exchangers are given, because the results in the case of all shell-and-tube heat exchangers show the same trend. The exergetic plant efficiency decreases linearly as shown in figure 10a, but the decrease is less strong than in the case when ideal components the results of the ideal case are shown in Walraven et al. [4] - are used. Figure 10b shows the pinch-pointtemperature difference between the working fluid and the cooling fluid. This temperature difference decreases with increasing cooling-water inlet temperature, so that the condenser temperature remains relatively low.

\subsection{Influence cooling-fluid mass flow}

In this section the cooling-water mass flow is varied between 200 and $2000 \mathrm{~kg} / \mathrm{s}$. The other parameters are given in table 3 and only the results for ORCs with all plate heat exchangers are shown; the results for ORCs with all shell-and-tube heat exchangers are analogous. Figure 11a shows the exergetic plant efficiency as a function of the cooling-water mass flow. At low values of the cooling-water mass flow, an increase of this mass flow will lead to an increase in the plant efficiency. This efficiency reaches a maximum for a mass flow of about $800 \mathrm{~kg} / \mathrm{s}$ for ORCs with Propane and for a mass flow of about $1100 \mathrm{~kg} / \mathrm{s}$ for ORCs with Isobutane, R134a, R218 and RC318. For the other investigated fluids the maximum is reached at higher mass flows. The same effect is also seen when shell-and-tube heat exchangers are used, but it is then less strong. The maximum in the exergetic plant efficiency at a certain mass flow rate is explained by figure $11 \mathrm{~b}$, which shows the minimum temperature in the condenser. This temperature decreases with increasing cooling water mass flow, which results in a better plant efficiency. The pressure drop in the cooling water increases on the other hand. The combination of the increasing pressure drop and increasing mass flow results in an increasing pumping power. This effect becomes more important than the decreasing condenser temperature, which results in a maximum plant efficiency for a certain cooling fluid mass flow rate.

Figure 11c shows the pinch-point-temperature difference in the condenser. If the cooling fluid mass flow rate increases, the cooling-fluid outlet temperature will decrease and the curve of the cooling fluid will become flatter in a temperature-heat diagram. In order to keep the average temperature difference in the condenser 


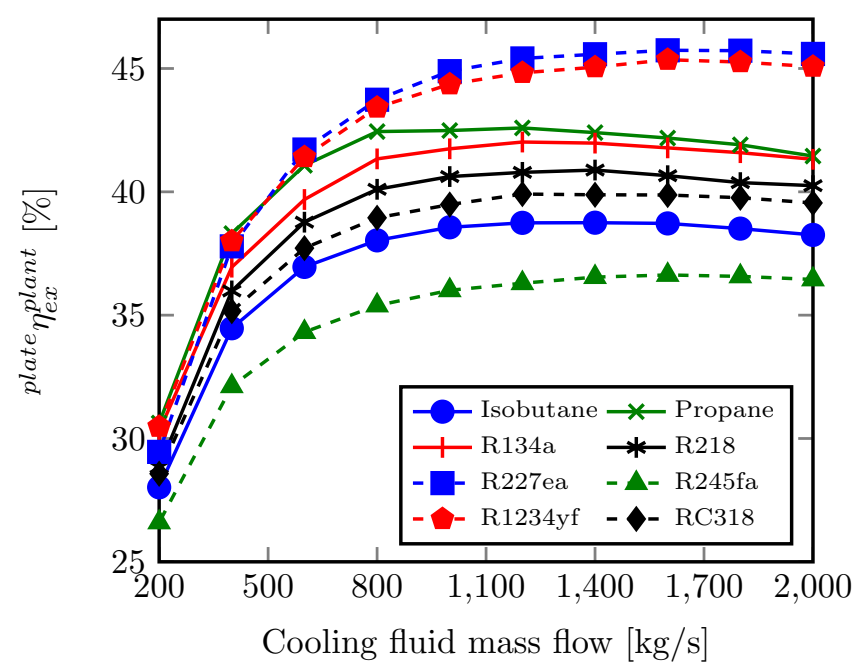

(a) Exergetic plant efficiency

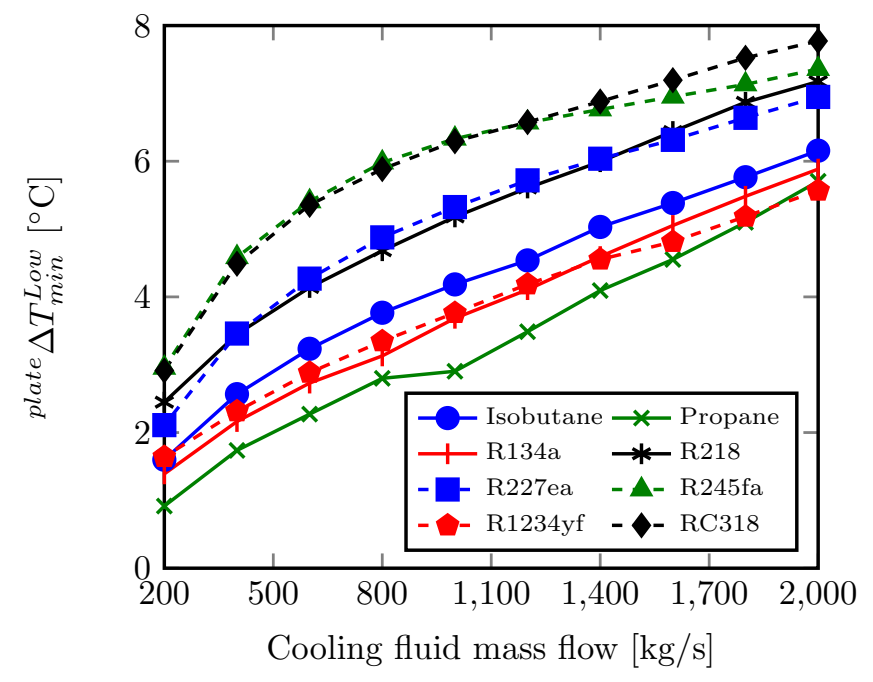

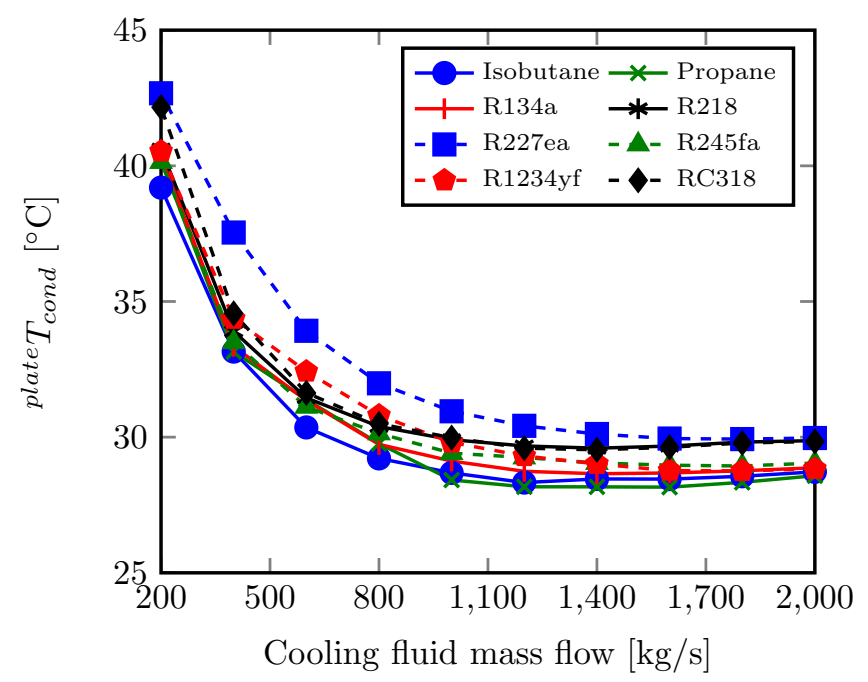

(b) Condenser temperature

(c) Pinch-point-temperature difference in condenser

Figure 11: Exergetic plant efficiency (a), minimum temperature in the condenser (b) and $\Delta T_{\min }^{\text {Low }}$ (c) for single-pressure, simple ORCs with all plate heat exchangers for different fluids.

more or less constant (the total amount of available heat exchanger surface is limited), the pinch-pointtemperature difference in the condenser has to increase.

\subsection{Influence number of pressure levels}

The effect on the plant efficiency of adding extra pressure levels is shown in figure 12a. The reference parameters are used (table 3 ) and the results for both plate heat exchangers and shell-and-tube heat exchangers are shown.

Adding an extra pressure level to subcritical cycles (Isobutane, Propane, R134a, R245fa) has a positive effect on the plant performance. Transcritical cycles do not use the second pressure level and their plant efficiency remains therefore constant. Double-pressure, subcritical cycles can cool down the heat source more than 


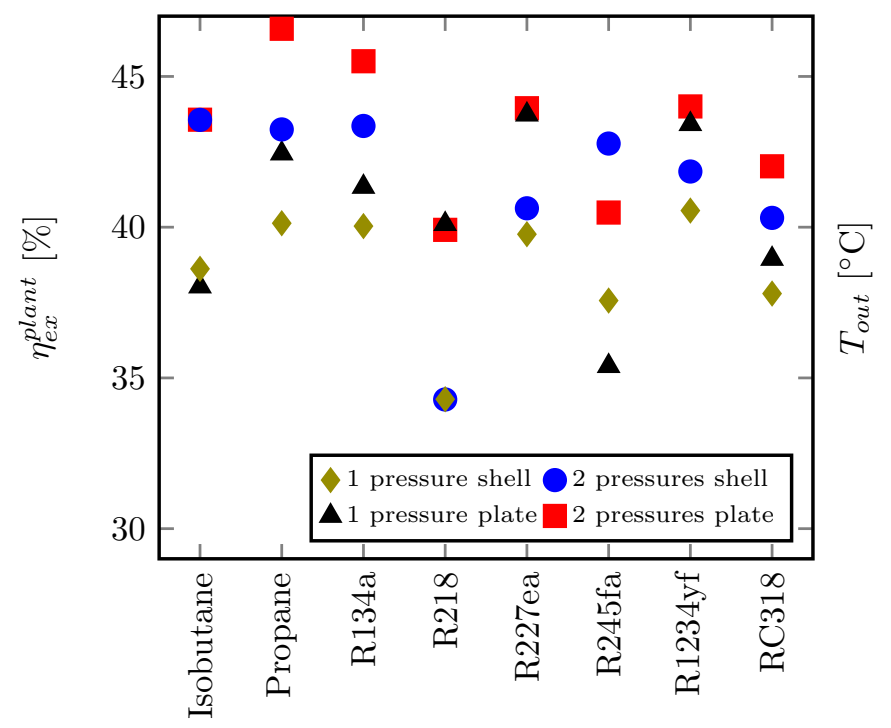

(a) Exergetic plant efficiency

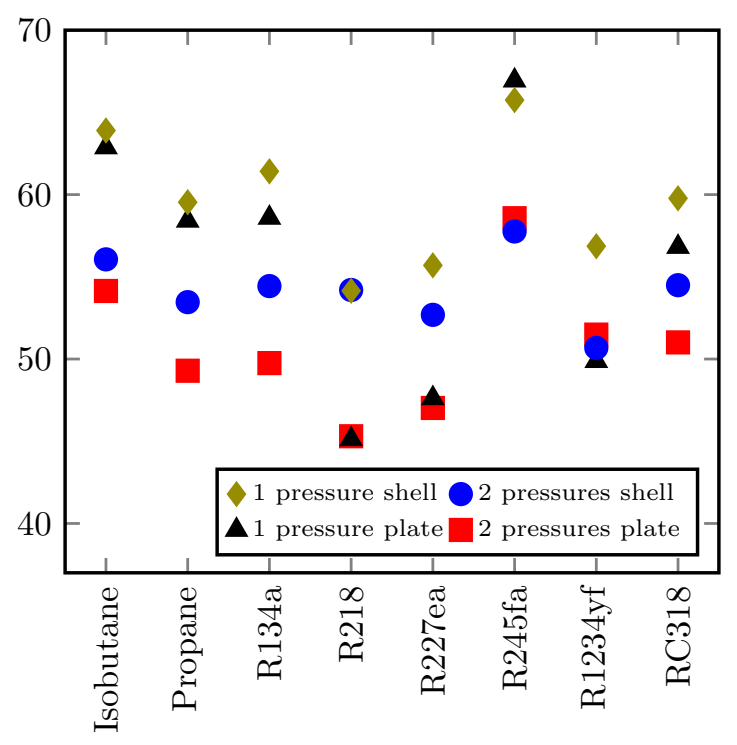

(b) Outlet temperature

Figure 12: Exergetic plant efficiency (a) and heat source outlet temperature (b) for simple ORCs with all plate heat exchangers or all shell-and-tube heat exchangers for different fluids.

single-pressure subcritical cycles (figure 12b) and obtain better plant efficiencies, while the energetic cycle efficiency remains about constant when adding a second pressure level.

\section{Conclusions}

The system optimization of different configurations of ORCs with both plate heat exchangers and shelland-tube heat exchangers is compared in this paper. Models for heat exchangers used in single-phase flow, evaporation and condensation which are available in the literature are implemented and added to a previous developed ORC-model.

It is shown that ORCs with all plate heat exchangers perform mostly better than ORCs with all shelland-tube heat exchangers. The disadvantage of plate heat exchangers with an equal number of passes at both sides of the exchanger is that the geometry of both sides of the heat exchanger are identical, which can lead to an inefficient heat exchanger when the two fluid streams require strongly different channel geometries.

The influence of the maximum allowed heat-exchanger surface, heat-source inlet temperature, constraint on the heat-source outlet temperature, cooling-fluid inlet temperature and mass flow and the number of pressure levels on the performance of the ORC have been investigated. It is shown that the efficiency of an ORC increases with increasing heat-exchanger surface and that every fluid has a heat-source inlet temperature for which the plant efficiency is maximal. Recuperated ORCs are only useful when the heat-source outlet temperature is constrained and the best double-pressure subcritical ORCs perform better than the best single-pressure transcritical cycles.

The cooling-fluid inlet temperature and mass flow have a strong influence on the performance of the ORC. The next step in the system optimization is to model the cooling system and to include it in the optimization. 


\section{Nomenclature}

Greek

$\beta \quad$ Corrugation angle [ $\left.{ }^{\circ}\right]$

$\Delta p \quad$ Pressure drop $[\mathrm{Pa}]$

$\Delta T$ Temperature difference $\left[{ }^{\circ} \mathrm{C}\right]$

$\eta \quad$ Efficiency [-]

$\Lambda \quad$ Corrugation width $[\mathrm{m}]$

$\mu \quad$ Dynamic viscosity [Pa s]

$\Phi \quad$ Area enlargment factor [-]

$\rho \quad$ Density $\left[\mathrm{kg} / \mathrm{m}^{3}\right]$

$\theta \quad$ Angle [ $\left.{ }^{\circ}\right]$ 


\section{Roman}

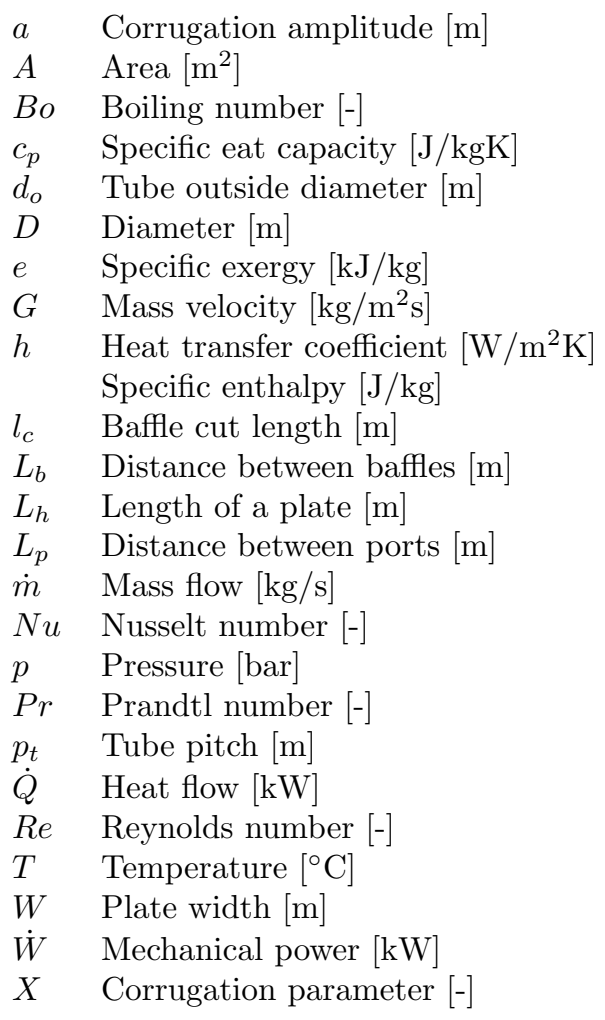




\section{Sub-and superscripts}

$\begin{array}{ll}0 & \text { Dead state } \\ 1-9 & \text { Number of the state } \\ a c & \text { Acceleration } \\ \text { cycle } & \text { Cycle } \\ \text { en } & \text { Energetic } \\ \text { ex } & \text { Exergetic } \\ f r & \text { Frictional } \\ h & \text { Hydraulic } \\ \text { id } & \text { Ideal } \\ \text { in } & \text { Inlet } \\ \text { max } & \text { Maximum } \\ \text { min } & \text { Minimum } \\ \text { net } & \text { Nett } \\ l & \text { Longitudinal } \\ \text { otl } & \text { Outermost tubes } \\ \text { out } & \text { Outlet } \\ \text { plant } & \text { Plant } \\ s & \text { Shell } \\ \text { source } & \text { Heat source } \\ t & \text { Transverse } \\ \text { tot } & \text { Total } \\ \text { wf } & \text { Working fluid }\end{array}$

\section{Acknowledgments}

Daniël Walraven is supported by a VITO doctoral grant. The valuable discussions on optimization with Joris Gillis (KU Leuven) are gratefully acknowledged and highly appreciated.

\section{References}

[1] J. Tester, B. Anderson, A. Batchelor, D. Blackwell, R. DiPippo, E. Drake, J. Garnish, B. Livesay, M. Moore, K. Nichols, The Future of Geothermal Energy: Impact of Enhanced Geothermal Systems (EGS) on the United States in the 21st Century, Tech. Rep., Massachusetts Institute of Technology, Massachusetts, USA, 2006.

[2] Y. Dai, J. Wang, L. Gao, Parametric optimization and comparative study of organic Rankine cycle (ORC) for low grade waste heat recovery, Energy Conversion and Management 50 (3) (2009) 576-582.

[3] B. Saleh, G. Koglbauer, M. Wendland, J. Fischer, Working fluids for low-temperature organic Rankine cycles, Energy 32 (7) (2007) 1210-1221.

[4] D. Walraven, B. Laenen, W. Dhaeseleer, Comparison of thermodynamic cycles for power production from low-temperature geothermal heat sources, Energy Conversion and Management 66 (2013) 220-233.

[5] D. Walraven, B. Laenen, W. Dhaeseleer, Optimum configuration of shell-and-tube heat exchangers for the use in lowtemperature organic Rankine cycles, Energy Conversion and Management 83 (2014) 177-187.

[6] H. Madhawa Hettiarachchi, M. Golubovic, W. M. Worek, Y. Ikegami, Optimum design criteria for an organic Rankine cycle using low-temperature geothermal heat sources, Energy 32 (9) (2007) 1698-1706.

[7] S. Quoilin, V. Lemort, J. Lebrun, Experimental study and modeling of an Organic Rankine Cycle using scroll expander, Applied Energy 87 (4) (2010) 1260-1268.

[8] Z. Shengjun, W. Huaixin, G. Tao, Performance comparison and parametric optimization of subcritical Organic Rankine Cycle (ORC) and transcritical power cycle system for low-temperature geothermal power generation, Applied Energy 88 (8) (2011) 2740-2754.

[9] A. Domingues, H. Santos, M. Costa, Analysis of vehicle exhaust waste heat recovery potential using a Rankine cycle, Energy 49 (2013) 71-85.

[10] A. Franco, M. Villani, Optimal design of binary cycle power plants for water-dominated, medium-temperature geothermal fields, Geothermics 38 (4) (2009) 379-391.

[11] G. F. Hewitt, Hemisphere handbook of heat exchanger design, Hemisphere Publishing Corporation New York, 1990. 
[12] R. K. Shah, D. P. Sekulić, Fundamentals of heat exchanger design, John Wiley and Sons, Inc., 2003.

[13] H. Martin, A theoretical approach to predict the performance of chevron-type plate heat exchangers, Chemical Engineering and Processing 35 (4) (1996) 301-310.

[14] Z. H. Ayub, Plate heat exchanger literature survey and new heat transfer and pressure drop correlations for refrigerant evaporators, Heat Transfer Engineering 24 (5) (2003) 3-16.

[15] E. Djordjevic, S. Kabelac, Flow boiling of R134a and ammonia in a plate heat exchanger, International Journal of Heat and Mass Transfer 51 (25) (2008) 6235-6242.

[16] D.-H. Han, K.-J. Lee, Y.-H. Kim, Experiments on the characteristics of evaporation of R410A in brazed plate heat exchangers with different geometric configurations, Applied Thermal Engineering 23 (10) (2003) 1209-1225.

[17] D.-H. Han, K.-J. Lee, Y.-H. Kim, The characteristics of condensation in brazed plate heat exchangers with different chevron angles, Journal of the Korean Physical Society 43 (2003) 66-73.

[18] A. Jokar, M. H. Hosni, S. J. Eckels, Dimensional analysis on the evaporation and condensation of refrigerant R-134a in minichannel plate heat exchangers, Applied thermal engineering 26 (17) (2006) 2287-2300.

[19] G. A. Longo, R410A condensation inside a commercial brazed plate heat exchanger, Experimental Thermal and Fluid Science 33 (2) (2009) 284-291.

[20] B. Thonon, A. Bontemps, Condensation of pure and mixture of hydrocarbons in a compact heat exchanger: experiments and modelling, Heat transfer engineering 23 (6) (2002) 3-17.

[21] E. Lemmon, M. Huber, M. Mclinden, NIST Reference Fluid Thermodynamic and Transport Properties REFPROP, The National Institute of Standards and Technology (NIST), version 8.0, 2007.

[22] J. R. Martins, P. Sturdza, J. J. Alonso, The complex-step derivative approximation, ACM Transactions on Mathematical Software (TOMS) 29 (3) (2003) 245-262.

[23] P. Peterson, F2PY: a tool for connecting Fortran and Python programs, International Journal of Computational Science and Engineering 4 (4) (2009) 296-305.

[24] J. Andersson, J. Åkesson, M. Diehl, CasADi - A symbolic package for automatic differentiation and optimal control, in: S. Forth, P. Hovland, E. Phipps, J. Utke, A. Walther (Eds.), Recent Advances in Algorithmic Differentiation, vol. 87 of Lecture Notes in Computational Science and Engineering, Springer Berlin Heidelberg, 297-307, 2012.

[25] C. Büskens, D. Wassel, The ESA NLP Solver WORHP, in: Modeling and Optimization in Space Engineering, Springer, $85-110,2013$

\section{Appendix A. Heat transfer and pressure drop correlations}

The heat-transfer and pressure-drop correlations used in this paper are given in this appendix.

\section{A.1. Single-phase heat transfer and pressure drop}

The model of Martin [13] is used to calculate the pressure drop and heat transfer coefficient in chevron-type plate heat exchangers for single-phase flows. The frictional-pressure drop for single-phase flow in one plate is given by:

$$
\left[\Delta p_{\text {single }}^{\text {plate }}\right]_{f r}=4 \frac{f_{\text {single }}^{\text {plate }} L_{p}}{D_{h}} \frac{G^{2}}{2 \rho},
$$

with $f_{\text {single }}^{\text {plate }}$ the Fanning friction factor, $G=\frac{\dot{m}}{2 a W N_{p}}$ the mass velocity and $N_{p}$ the number of channels. The Fanning friction factor is given by:

$$
\frac{1}{\sqrt{f_{\text {single }}^{\text {plate }}}}=\frac{\cos \beta}{\left(0.045 \tan \beta+0.09 \sin \beta+\frac{f_{0}}{\cos \beta}\right)^{0.5}}+\frac{1-\cos \beta}{\sqrt{3.8 f_{1}}},
$$

with $f_{0}$ the Fanning friction coefficient if $\beta=0^{\circ}$ and $f_{1}$ the Fanning friction coefficient if $\beta=90^{\circ}$. These coefficients are given by:

$$
\begin{gathered}
f_{0}=\left\{\begin{array}{ll}
\frac{16}{R e} & \text { for } R e<2000 \\
(1.56 \ln R e-3.0)^{-2} & \text { for } R e \geq 2000
\end{array},\right. \\
f_{1}= \begin{cases}\frac{149.25}{R e}+0.9625 & \text { for } R e<2000 \\
\frac{9.75}{R e^{0.289}} & \text { for } R e \geq 2000\end{cases}
\end{gathered}
$$

where $R e=\frac{G D_{h}}{\mu}$ is the Reynolds number. 
The hydrostatic-pressure drop is neglected because the fluids flow alternately up and down and the hydrostatic pressure drop is therefore alternately positive and negative. Both are about equal and can therefore be assumed to neutralize each other.

The heat-transfer coefficient is calculated as:

$$
h=\frac{k}{D_{h}} 0.205 \operatorname{Pr}^{1 / 3}\left(\frac{\mu_{m}}{\mu_{w}}\right)^{1 / 6}\left(f_{\text {single }}^{\text {plate }} \operatorname{Re}^{2} \sin 2 \beta\right)^{0.374},
$$

with $\mu_{m}$ the viscosity of the bulk fluid and $\mu_{w}$ the viscosity of the fluid at the wall. The difference between these viscosities is neglected. $\operatorname{Pr}$ is the Prandtl number.

\section{A.2. Heat transfer and pressure drop while evaporating}

Han et al. [16] developed correlations for the pressure drop and heat transfer in chevron-type plate heat exchangers during evaporation. The frictional pressure drop in one plate during evaporation is:

$$
\left[\Delta p_{\text {evap }}^{\text {plate }}\right]_{f r}=4 \frac{f_{\text {evap }}^{\text {plate }} L_{p}}{D_{h}} \frac{G_{e q}^{2}}{2 \rho_{l}},
$$

with $G_{e q}$ the equivalent mass velocity, defined as:

$$
G_{e q}=G\left[1-x+x\left(\rho_{l} / \rho_{v}\right)^{1 / 2}\right]
$$

where $\rho_{l}$ and $\rho_{v}$ are the densities of saturated liquid and saturated vapor, respectively.

The correlation for the Fanning friction factor is given by:

$$
f_{\text {evap }}^{\text {plate }}=c_{1} R e_{\text {eq }}^{c_{2}}
$$

with

$$
\begin{aligned}
c_{1} & =64710\left(\frac{\Lambda}{D_{h}}\right)^{-5.27} \beta^{-3.03}, \\
c_{2} & =-1.314\left(\frac{\Lambda}{D_{h}}\right)^{-0.62} \beta^{-0.47}, \\
R e_{e q} & =\frac{G_{e q} D_{h}}{\mu_{l}}
\end{aligned}
$$

The acceleration pressure drop is given by:

$$
{ }^{a c} \Delta p_{\text {evap }}^{\text {plate }}=\left(\frac{G_{e q}^{2} x}{\rho_{l}-\rho_{v}}\right)_{\text {out }}-\left(\frac{G_{e q}^{2} x}{\rho_{l}-\rho_{v}}\right)_{i n} .
$$

The heat transfer coefficient is correlated as:

$$
h=\frac{k}{D_{h}} c_{3} R e_{e q}^{c_{4}} B o_{e q}^{0.3} \operatorname{Pr}_{l}^{0.4},
$$

with:

$$
\begin{aligned}
c_{3} & =2.81\left(\frac{\Lambda}{D_{h}}\right)^{-0.041} \beta^{-2.83}, \\
c_{4} & =0.746\left(\frac{\Lambda}{D_{h}}\right)^{-0.082} \beta^{0.61}, \\
B o_{e q} & =\frac{\dot{q}}{G_{e q}\left(h_{v}-h_{l}\right)} .
\end{aligned}
$$


$B o_{e q}$ is the equivalent boiling number.

The experiments performed by Han et al. [16] were done for $\beta=45,55$ and $70^{\circ}, G=13-34 \mathrm{~kg} / \mathrm{m}^{2} \mathrm{~s}$ and a heat flux of $2.5-8.5 \mathrm{~kW} / \mathrm{m}^{2}$, while using $\mathrm{R} 22$ and $\mathrm{R} 410 \mathrm{a}$ as working fluids.

\section{A.3. Heat transfer and pressure drop while condensing}

The correlations for the pressure drop and the heat transfer coefficient while condensing are given by Han et al. [17] and are analogous to the ones for the evaporation, albeit with differently defined coefficients $c_{i}$ and $h$ :

$$
\begin{aligned}
{\left[\Delta p_{\text {cond }}^{\text {plate }}\right]_{f r} } & =4 \frac{f_{\text {cond }}^{\text {plate }} L_{p}}{D_{h}} \frac{G_{e q}^{2}}{2 \rho_{l}}, \\
f_{\text {cond }}^{\text {plate }} & =c_{5} R e_{\text {eq }}^{c_{6}}, \\
c_{5} & =3521.1\left(\frac{\Lambda}{D_{h}}\right)^{4.17} \beta^{-7.75}, \\
c_{6} & =-1.024\left(\frac{\Lambda}{D_{h}}\right)^{0.0925} \beta^{-1.3}, \\
h & =\frac{k}{D_{h}} c_{7} \operatorname{Re}_{e q}^{c_{8}} \operatorname{Pr}_{l}^{1 / 3}, \\
c_{7} & =11.22\left(\frac{\Lambda}{D_{h}}\right)^{-2.83} \beta^{-4.5}, \\
c_{8} & =0.35\left(\frac{\Lambda}{D_{h}}\right)^{0.23} \beta^{1.48} .
\end{aligned}
$$

The experiments performed by Han et al. [17] were done for $\beta=45,55$ and $70^{\circ}$ and $G=13-34 \mathrm{~kg} / \mathrm{m}^{2} \mathrm{~s}$, while using R22 and R410a as working fluids. 